\title{
Confúcio e o fim da filosofia: análise do capítulo IX do Tratado da Piedade Filial traduzido por Joaquim Guerra (1984)
}

\section{Antonio José Bezerra de MENEZES JR. ${ }^{1}$}

As traduções dos Clássicos Chineses feitas pelo padre jesuíta português Joaquim Angélico de Jesus Guerra (1908-1993), em contraste com as célebres traduções do pastor escocês James Legge (1815-1897), que segue a ortodoxia neo-confuciana de Zhuxi (朱喜, 1130-1200), procuram revelar sentidos filosóficos mais profundos em sentenças excessivamente trivializadas. Para isso, apoia-se no sofisticado aparato linguístico proporcionado pelo seu Dicionário Chinês-Português de Análise Semântica Universal (Guerra, 1981), no qual compilou diversos léxicos chineses antigos, recuperando muitos significados raros.

Um bom exemplo disso podemos encontrar no capítulo IX do "Manual da Piedade Familiar" (朱喜 Xiào Jing), atribuído ao filósofo Zeng Zi (曾子, 505-436 a.C.) e incluído no Quadrivo-

1 Professor do Curso de Chinês da Faculdade de Filosofia, Letras e Ciências Humanas da Universidade de São Paulo, Brasil.antonio.menezes@usp.br 
lume de Confúcio (Guerra, 1984). Nesse texto em particular, ao contrário das demais traduções nas quais Joaquim Guerra trava um intenso debate com James Legge, o tradutor português afirma não ter cotejado o seu trabalho com outras traduções. A razão principal disso é que o referido tratado não foi incluído na coleção "The Chinese Classics” (Oxford, 1861-1872), de James Legge, que Joaquim Guerra estudou detidamente, mas foi incluído apenas na grande coleção Sacred Books of the East (volume III, 1879), editada por F. Max Muller (1823-1900), à qual o sinólogo jesuíta não obteve acesso.

Vejamos agora o seguinte trecho do capítulo IX do "Manual da Piedade Familiar", na tradução de Joaquim Guerra:

故不愛其親而愛他人者, 謂之悖德 ; 不敬其親而敬 他人者, 謂之悖禮。以順則逆, 民無則焉。不在於 善, 而皆在於凶德。雖得之, 君子不貴也。

Se alguém não ama os seus Pais, mas ama a outras pessoas, chama-se a isso uma virtude pervertida. Não respeitar os Pais e respeitar a outros é uma perversão de relações. Se nessas coisas naturais, se põe escândalo, o povo não terá que imitar. Se não se tem o bem à vista, mas só maus exemplos, embora goze de favor, o Homem digno não lhe dá valor. (GUERRA, 1984, p. 949)

Essa passagem é assim traduzida por James Legge:

Hence, he who does not love his parents, but loves other men, is called a rebel against virtue, and he who does not revere his parents, but reveres other men, is called a rebel against propriety. When (the ruler) himself thus 
acts contrary to (the principles) which should place him in accord (with all men), he presents nothing for the people to imitate. He has nothing to do with what is good, but entirely and only with what is injurious to virtue. Though he may get (his will, and be above others), the superior man does not give him his approval. (LEGGE, 1879, p. 479)

Na recente tradução de Rosemont Jr. e Ames (2009), o sentido varia pouco:

It is for this reason that to love others while not loving one's parentes is depravity (de), and to respect others while not respecting one's parentes is a sacrilege (li). To base the norms to be followed (shun) upon such perversity would leave the people without any standards. No decency is to be found in this-only decadence (de). Even though such persons might enjoy a measure of sucess, exemplar persons (junzi) would not esteem them." (ROSEMONT JR.; AMEs, 2009, p. 110-111)

No início desse trecho, Confúcio reafirma que, sendo o respeito e o amor aos pais o princípio da Piedade Filial, na falta disso, a ordem moral da sociedade estará comprometida, ainda que exista uma ordem política visível. ${ }^{2}$ A conclusão do trecho, porém, é que aparece trivializada nas traduções inglesas: "o homem de caráter nobre (君子 jūnž̃) não aprova o governante injusto” (LEGGE, 1879) ou “o homem de caráter nobre (君子 jūnzî) não

2 Também podemos notar aqui um eco da crítica do Confucionismo às doutrinas rivais do Moísmo e do Legismo. 
estima pessoas imorais mesmo que tenham sucesso" (ROSEMONT JR.; Ames, 2009). Em outras palavras, afirmar que o justo reprova o ímpio é por demais trivial. Considerando o contexto de uma sociedade decadente e de um poder político corrompido e corruptor, é que Joaquim Guerra apresenta a sua tradução na qual o homem de caráter nobre (君子 jūnzî) nada deve estimar daquilo que eventualmente obtiver (cargos ou favores) sob pena de desviar-se da norma moral (道 dào).

Nas traduções inglesas, o texto prossegue fazendo a distinção entre o homem corrupto e o homem de caráter nobre (君子 jūnzî), mostrando as qualidades deste último de forma idealizada:

君子則不然, 言思可道, 行思可樂, 德義可學, 作 事可法，容止可觀，進退可度。

It is not so with the superior man. He speaks, having thought whether the words should be spoken; he acts, having thought whether his actions are sure to give pleasure. His virtue and righteousness are such as will be honored; what he initiates and does is fit to be imitated; his deportment is worthy of contemplation; his movements in advancing or retiring are all according to the proper rule. (LeGGe, 1879, p. 480)

Exemplary persons (junzi) are nothing like this. They are concerned that what they say be credible, and what they do be a source of enjoyment (le). Their excellence (de) and sense of appropriateness (yi) is to be esteemed and they are to be emulated (fa) in what they do. In their bearing and deportment they are to be looked up 
to, and in their undertankings they are to be taken as a standard. (Rosemont JR.; Ames, 2009, p. 111)

Joaquim Guerra, porém, considera justamente a hipótese contrária, no caso de o homem de caráter nobre (君子 jūnž̃) desviar-se da norma moral (道 dào) e, portanto, não realizar a sua humanidade, trazendo, com isso, graves consequências para ele mesmo e para a sociedade:

君子則不然, 言思可道, 行思可樂, 德義可學, 作 事可法, 容止可觀, 進退可度。

Se o Sábio se não realiza, será que as palavras e os propósitos ainda têm sentido? Ainda haverá prazer no que se faz? O ideal da virtude ainda se poderá honrar? E no que se faz ainda haverá uma norma? Avançar e recuar poderão ser ainda um procedimento avisado? (GUERRA, 1984, p. 949)

Essa tradução é perfeitamente possível tomando-se os caracteres 然 (rán) e 可 (kě), ambos no sentido (5), tal como Joaquim Guerra registra em seu dicionário: 


\begin{tabular}{|c|l|}
\hline 然 & $\begin{array}{l}\text { 1) Sim, certamente, deveras, tal qual, realmente, } \\
\text { assim mesmo; 2) Mas, contudo, todavia, nesse } \\
\text { Jen.6ih }\end{array}$ \\
rán & $\begin{array}{l}\text { 4) Aparência, como, tal como; 5) Ser, existir, ente, } \\
\text { entidade; 6) Suf. De advérbios de modo; 7) Apro- } \\
\text { var, aquiescer, embora. (GuERRA, 1981, p. 327) }\end{array}$ \\
\hline Xhau.0db & $\begin{array}{l}\text { 1) Habilidade, hábil, ser capaz de, poder, po- } \\
\text { der ser, possível, viável, viabilidade, permitido; } \\
\text { 2) Aval, autorização, anuir, anuência, aprovar, } \\
\text { aprovação; 3) Aguentar, tolerar; 4) Convenien- } \\
\text { te, apropriado, Acomodado, afeito, habituado, } \\
\text { calhar bem, acertar, acertado, acerto; 5) Como? } \\
\text { Pode lá ser? 6) Nesse caso, mas só que. (GuERRA, } \\
\text { 1981, p. 779) }\end{array}$ \\
\hline
\end{tabular}

O problema da linguagem que perde o sentido retoma a questão da "retificação dos nomes", um dos temas fundamentais em Confúcio, como podemos ler em Os Analectos XIII, 3: "Quando os nomes não são corretos, a linguagem fica sem sentido. Quando a linguagem fica sem sentido, nenhum assunto pode ser resolvido" (LEYs, 2005, p. 69).

Concluindo o capítulo IX do "Manual da Piedade Familiar", diz Confúcio:

以臨其民。是以其民畏而愛之, 則而象之。故能成 其德教, 而行其政令。

No governo do povo, começa-se pelo respeito para chegar ao amor. Se o bom exemplo se evidencia, então se 
poderá realizar a educação na virtude, e exercer um governo autêntico. (GuERRA, 1984, p. 949)

Confúcio coloca no governo do povo os mesmos princípios que formam a Piedade Filial: o respeito e o amor. Embora pareça pequena, a virtude da Piedade Filial é de importância fundamental, pois um pequeno desvio no início poderá mais tarde resultar em grandes desvios: o governo que nega a justiça e o intelecto que nega a verdade.

Somente a educação na virtude, essência do Confucionismo, é que irá produzir um governo autêntico e não um desgoverno que ofende ao Céu e que se transforma ele próprio em castigo até que o Mandato do Céu (天命 tiān mìng), conforme a historiografia tradicional chinesa, seja retirado do governante ímpio e dado ao governante justo.

\section{Conclusão}

Todas as traduções aqui apresentadas do capítulo IX do "Manual da Piedade Familiar" são perfeitamente cabíveis, diferentemente do caso de Analectos VII,11, no qual a singular tradução de Joaquim Guerra é indubitavelmente a mais acertada (Menezes JR., 2013, p. 93-103). Porém a tradução do sinólogo português possui o mérito de recolocar o pensamento confuciano em termos sempre mais agudos.

Confúcio buscava a sabedoria no passado. Não se definia como um inventor, mas um transmissor da verdade revelada nos clássicos da antiguidade (Analectos VII, 1 e VII, 19). Desse modo, o sábio que não se realiza (por descumprir os deveres elementares da piedade) representa o abandono dessa vocação e a sua hegemonia no plano cultural terá como consequência o fim da filosofia. 


\section{Referências}

Guerra, Joaquim A. de Jesus. Dicionário Chinês-Português de Análise Semântica Universal. Macau: Jesuítas Portugueses, 1981.

Guerra, Joaquim A. de Jesus. Manual da Piedade Familiar. In: Quadrivolume de Confúcio. Macau: Jesuítas Portugueses, 1984. p. 915-979.

Legge, James. The Hsiao King. In: Muller, Friederich Max (Ed.). Sacred Books of the East. Oxford: Claredon, 1879. v. III, p. 483-522.

Leys, Simon. Os Analectos. Tradução, apresentação e notas de Simon Leys (Pierre Ryckmans). São Paulo: Martins Fontes, 2005.

Menezes JR., Antonio José Bezerra de. Joaquim Guerra S.J. (1908-1993): Releitura universalizante dos Clássicos Chineses. São Paulo, 2013. Tese (Doutorado em Letras) - Faculdade de Filosofia, Letras e Ciências Humanas, Universidade de São Paulo, Brasil, 2013. Disponível em: <http://www.teses.usp.br/teses/ disponiveis/8/8150/tde-13032014-124801/pt-br.php>. Acesso em: 10 jan. 2015.

Rosemont JR., Henry; Ames, Roger T. The Chinese Classic of Family Reverence: A Philosophical Translation of the Xiaojing. Honolulu: University of Hawai'i Press, 2009.

Menezes JR., Antonio José Bezerra de. Confúsio e o fim da filosofia: análise do capítulo IX do Tratado da Piedade Filial traduzido por Joaquim Guerra (1984). In: SimAs, Monica (Org.) Estudos sobre Macau e outros orientes. São Paulo: Paulistana, 2017. p. 16-23. 